\title{
Gegar Bahasa pada Program Pertukaran Mahasiswa Indonesia di Jepang: Sebuah Studi Kasus
}

\section{Language Shock in Indonesian-Student Exchange Program in Japan: A Case Study}

\author{
Siti Yulidhar Harunasari ${ }^{1}$ dan Nurhasanah Halim ${ }^{2, *}$ \\ ${ }^{1,2}$ STKIP Kusumanegara, Jakarta \\ ${ }^{1}$ Email: yulidhar1@stkipkusumanegara.ac.id \\ ${ }^{2}$ Corresponding Email: nurhasanah halim@stkipkusumanegara.ac.id
}

Received: 5 April 2021 Accepted: 27 August 2021 Published: 1 November 2021

\begin{abstract}
The purpose of this study was to describe the experience of a language learner in an Indonesian student exchange program in Japan aimed to enable students to learn the language and culture directly in their home country. This experience was captured through a descriptive case study conducted to obtain a clear picture of what happened and find out what aspects could cause language concussion; and how the influence of language shock on the social acculturation of language learners. Data were collected through observation and interviews. The results showed that the language shock experienced by the Research Subjects in the target language environment included linguistic aspects at the phonological and morphological levels. Sociolinguistic aspects at the level of the use of a variety of respect. Anxiety also occurs due to the loss of signs and symbols of social relationships commonly known by the Research Subjects. Therefore, cultural differences between Indonesia and Japan should be anticipated so as not to cause difficulties in carrying out social acculturation.
\end{abstract}

Keywords: culture shock, language shock, student exchange program

Abstrak: Penelitian ini bertujuan menggambarkan pengalaman seorang pemelajar bahasa dalam program pertukaran mahasiswa Indonesia di Jepang yang bertujuan agar mahasiswa dapat belajar bahasa dan budaya langsung di negara asalnya. Pengalaman ini dipotret melalui studi kasus deskriptif yang dilakukan untuk memperoleh gambaran yang jelas mengenai apa yang terjadi dan untuk mengetahui aspek-aspek apa sajakah yang dapat menimbulkan gegar bahasa; dan bagaimana pengaruh gegar bahasa terhadap akulturasi sosial pemelajar bahasa. Pengumpulan data dilakukan melalui observasi dan wawancara. Hasil penelitian menunjukkan bahwa gegar bahasa yang dialami subjek penelitian dalam lingkungan bahasa target meliputi aspek linguistik dalam tataran fonologi dan morfologi, dan dalam aspek sosiolinguistik pada tataran penggunaan ragam hormat. Kecemasan juga terjadi akibat hilangnya tanda dan simbol hubungan sosial yang biasa dikenal oleh subjek penelitian. Oleh karena itu, perbedaan budaya antara Indonesia dengan Jepang selayaknya diantisipasi agar tidak menimbulkan kesulitan dalam melakukan akulturasi sosial.

Kata kunci: gegar budaya, gegar bahasa, program pertukaran mahasiswa

To cite this article:

Harunasari, S. Y., \& Halim, N. (2021). Gegar Bahasa pada Program Pertukaran Mahasiswa Indonesia di Jepang: Sebuah Studi Kasus. Diglosia: Jurnal Kajian Bahasa, Sastra, dan Pengajarannya, 4(4), 401-412. https://doi.org/10.30872/diglosia.v4i4.212 


\section{A. PENDAHULUAN}

Program pertukaran mahasiswa ke luar negeri membawa banyak perubahan positif. Namun, hanya sedikit pengalaman saat mengikuti program yang diangkat dalam bentuk penelitian ilmiah agar menjadi dorongan bagi mahasiswa lain mengambil manfaat dari perubahan tersebut (McKay, Lannegrand, Skues, \& Wise, 2020). Pertukaran mahasiswa biasanya adalah program yang mengharuskan mahasiswa menyelesaikan satu atau dua semester di perguruan tinggi mitra di luar negeri sebagai bagian dari pemenuhan syarat untuk memperoleh gelar mereka (Engle \& Engle, 2003). Pertukaran mahasiswa Indonesia dengan perguruan tinggi mitra di luar negeri merupakan salah satu bentuk fasilitas yang diberikan agar mahasiswa dapat belajar bahasa dan budaya langsung dari sumbernya. Keyakinan ini berasal dari pendapat bahwa bahasa adalah bagian dari kebudayaan (Koentjaraningrat, 1992).

Dalam kaitannya dengan pembelajaran bahasa asing, seorang pemelajar bahasa harus lebih dahulu merasa nyaman dalam budaya barunya, dan nyaman dalam melakukan komunikasi bersemuka untuk dapat menjalankan fungsi sebuah bahasa sebagai sarana komunikasi (Levine, 1993). Temuan penelitian Graham dan Brown (1996) menunjukkan bahwa kemampuan berbahasa seperti penutur asli dapat dicapai dengan adanya sikap positif dari pemelajar terhadap komunitas bahasa target dan hubungan baik dengan penutur asli bahasa target yang dikembangkan oleh si pemelajar. Sikap positif pemelajar kemudian ditunjukkan dari keberhasilannya melakukan akulturasi sosial yaitu integrasi pemelajar bahasa kedua ke dalam sebuah komunitas bahasa (Schumann,1986). Proses akulturasi ini memang bukan penyebab langsung terjadinya penguasaan bahasa target. Akulturasi adalah salah satu faktor utama yang bisa mendukung kesuksesan penguasaan bahasa target dalam suasana belajar secara alamiah. Schuman mengatakan bahwa "...acculturation as a remote cause brings the learner into contact with TL-speakers and verbal interaction with those speakers as a proximate cause brings about the negotiation of appropriate input which then operates as the immediate cause of language acquisition" (Schuman, 1986, p. 385). Mendukung hal tersebut, dalam penelitian lain disebutkan bahwa perkembangan pengetahuan siswa internasional tentang konteks budaya lebih meningkat dibandingkan siswa noninternasional-sebagai contoh, pengetahuan tentang bagaimana latar budaya yang berbeda memengaruhi reaksi dan interaksi dalam berkomunikasi dengan orang lain (Redden, 2010).

Dalam model akulturasi sosial Schumann, terdapat empat variabel sikap yang dapat memengaruhi kuantitas dan kualitas kontak yang dilakukan pemelajar bahasa kedua (Second Language Learner/2LL) dengan bahasa target (Target Language/TL), antara lain: (1) gegar bahasa (language shock), yaitu sejauh mana pengalaman berbicara menggunakan bahasa target membuat pemelajar merasa bodoh atau memalukan; (2) gegar budaya (culture shock) yaitu sejauh mana pemelajar merasakan disorientasi dan ketidaknyamanan dalam sebuah budaya baru; (3) ego permeability, yaitu kemampuan pemelajar untuk menerima sebuah identitas baru yang diasosiasikan dengan segala yang terkait dengan komunitas tutur; dan (4) motivation, tingkatan dan jenis keinginan yang dialami oleh pemelajar untuk menguasai bahasa target (Schumann,1986).

Bahasa adalah produk dari sebuah budaya; didahului dengan akulturasi yang merupakan rantai pertama dari keberhasilan belajar sebuah bahasa dan bagaimana kedua gegar ini berhubungan dengan akulturasi. Gegar budaya adalah proses 
transformatif pada tingkat individu dan masyarakat yang muncul akibat bentroknya dua kebudayaan (Cupsa, 2018). Dalam kaitannya dengan pembelajaran bahasa, gegar budaya merupakan sebuah konsep yang digunakan secara luas untuk menggambarkan pengalaman yang dialami seorang pendatang dalam sebuah lingkungan budaya baru. Pendatang tersebut tidak berbicara dengan bahasa yang sama dan tidak memahami secara detail perilaku sehari-hari lingkungan barunya, sering kali merasa kebingungan dan terdisorientasi. Ia bisa saja merasa tidak yakin, misalnya, kapan harus bersalaman; kapan harus merangkul ketika bertemu orang lain.

Gegar budaya bisa menjadi sebuah penghalang suksesnya kontak antarbudaya. Hal ini dikarenakan ketika seseorang memasuki sebuah lingkungan budaya baru dan bahasa yang berbeda, biasanya akan lebih memilih untuk berkomunikasi, memahami, memercayai, bekerja dan bermain dengan orang lain yang memiliki karakteristik yang serupa dengan dirinya sendiri (Byrne, 1969 dalam Lin, 2010). Hal ini diyakini karena setiap individu memiliki identitas budayanya sendiri, dan setiap orang dikenali dari kelompok budaya di mana ia berada. Dan penelitian (Triandis, 1990) juga menunjukkan, bahwa semakin besar perbedaan antara budaya asal dengan budaya baru, maka akan semakin tinggi kesulitan budaya yang akan dialami oleh pelajar internasional.

Bahasa dan budaya merupakan dua faktor yang saling memengaruhi dalam cara-cara yang kompleks dan bervariasi. Gegar budaya terjadi ketika seseorang berpindah dari satu budaya ke budaya yang lain; gegar bahasa terjadi ketika seseorang berpindah dari satu lingkungan bahasa ke lingkungan bahasa yang lain. Singkatnya, dikarenakan hubungan yang sangat erat antara budaya dan bahasa, maka gegar budaya dapat menyebabkan gegar bahasa. Bahasa sebagai komponen penting dari sebuah budaya juga memiliki pengaruh yang besar pada kompetensi antar budaya (intercultural competence) mahasiswa yang mengikuti program pertukaran tersebut dan pada siapa pun yang pindah ke sebuah lingkungan bahasa yang berbeda. Bahasa pada umumnya dipandang sebagai bagian dari budaya (Nida, 2003). Nida berpendapat bahwa faktor-faktor seperti entitas, peristiwa, keadaan, proses, dan karakteristik sebuah budaya memiliki pengaruh yang kuat pada konten bahasa yang digunakan dalam budaya tersebut. Perbedaan-perbedaan penyebab gegar bahasa, tidak saja terjadi antarbahasa, akan tetapi juga di dalam bahasa itu sendiri (Agar, 2002). Gegar bahasa yang terjadi dalam sebuah bahasa, dapat muncul dalam beragam aspek dan tataran, Di dalam penelitian ini, gegar bahasa dibatasi pada aspek linguistik dan sosiolinguistik.

Studi ini bertujuan untuk memberikan gambaran mengenai gegar budaya dan gegar bahasa yang mungkin terjadi dalam proses pembelajaran Bahasa asing dengan cara mengenali: (1) aspek-aspek yang dapat menimbulkan gegar bahasa; dan (2) pengaruh gegar bahasa terhadap akulturasi sosial pemelajar bahasa. Penelitian ini diharapkan dapat memberikan manfaat bagi pemelajar bahasa maupun penyelenggara program pertukaran mahasiswa agar dapat mengantisipasi, dan jika memungkinkan, memberikan intervensi untuk mengondisikan mahasiswa mengubah "gegar" menjadi motivasi untuk belajar bahasa dengan lebih baik.

\section{B. METODE}

Penelitian ini menggunakan pendekatan kualitatif Bogdan \& Biklen dalam mendefinisikan metodologi kualitatif sebagai prosedur penelitian yang menghasilkan 
data deskriptif berupa kata-kata tertulis atau lisan dari orang-orang dan perilaku yang dapat diamati. Metode yang digunakan adalah studi kasus, sesuai dengan tujuannya yang ingin menggambarkan karakteristik yang bermakna dari peristiwa kehidupan nyata antara lain pengalaman individu/subjek tunggal (Yin, 2003; Bogdan \& Biklen, 2007). Subjek penelitian adalah seorang mahasiswa semester VI jurusan Sastra Jepang Universitas Indonesia (selanjutnya disebut subjek penelitian), yang pada saat penelitian berlangsung tengah mengikuti program pertukaran mahasiswa pada jurusan International Relations, di sebuah perguruan tinggi di Fukuoka, Jepang.

Subjek penelitian mengikuti program pertukaran selama satu tahun. Situasi di mana Subjek merupakan peserta tunggal dari Indonesia menjadi salah satu alasan pemilihannya sebagai subjek penelitian. Data dikumpulkan melalui observasi cetak tampilan layar (print screen) akun Facebook milik subjek penelitian, dan wawancara semi terstruktur dengan subjek penelitian melalui video call, dan pertanyaan isian singkat melalui chat message. Pengumpulan data dilakukan 3 bulan setelah subjek penelitian tiba di Jepang untuk menjalani program pertukaran mahasiswa. Hal ini dilakukan untuk melihat aktivitas komunikasi Subjek melalui status Facebook pada tahap awal (initial state) sesuai pola umum gegar bahasa dan gegar budaya.

Analisis data dilakukan melalui langkah-langkah sebagai berikut. Reduksi data (data reduction), meliputi proses pemilihan (selecting), pemusatan perhatian (focusing), dan penyederhanaan (simplifying). Dalam tahap ini peneliti memilah dan memilih data yang relevan dengan tujuan penelitian. Penyajian data (data display), menyajikan data menjadi informasi. Daya yang terkumpul disusun dan disajikan secara sistematis melalui tabel. Penarikan kesimpulan (conclusion drawing/verification), melakukan verifikasi data berdasarkan data yang disajikan. Peneliti mencari makna dari data yang disajikan dengan melihat hubungan antar pola-pola yang berkembang. Sedangkan untuk meningkatkan validitas dan interpretasi hasil penelitian, peneliti menggunakan teknik within-method triangulation, yaitu penggunaan beragam metode pengumpulan data (Daytner, 2006).

\section{PEMBAHASAN}

Setelah direduksi, terdapat dua aspek yang dapat menimbulkan gegar bahasa dalam proses akulturasi sosial pada pertukaran mahasiswa Indonesia dengan mahasiswa Jepang yaitu aspek linguistik dan aspek sosiolinguistik Hasil reduksi ditampilkan berdasarkan tataran dan unsurnya pada Tabel 1 dan diikuti oleh pembahasan untuk menjawab pertanyaan penelitian.

Tabel 1. Bentuk Gegar Bahasa

\begin{tabular}{cll}
\hline Aspek & \multicolumn{1}{c}{ Tataran } & \multicolumn{1}{c}{ Unsur } \\
\hline Linguistik & Fonologi & 1. Fonem segmental \\
& & 2. Fonem suprasegmental \\
& Morfologi & 1. Kosakata \\
Sosiolinguistik & 2. Aksara Kanji \\
& Ragam bahasa & Ragam hormat \\
\hline
\end{tabular}

\section{Aspek Yang Dapat Menimbulkan Gegar Bahasa \\ a. Tataran Fonologi}

Gegar bahasa pada tataran fonologi terjadi pada unsur fonem segmental dan suprasegmental. Berikut pernyataan subjek pada saat wawancara. 
Kode
Fonologi (Fon)
Sumber

Wawancara melalui video call

\section{Data}

"Berbicara dengan penutur asli Jepang sangat sulit. Saya tidak memahami pelafalannya, kadang-kadang di telinga saya kedengarannya seperti orang berkumur...."

Dari unsur fonem segmental, dalam beberapa kasus, bunyi vokal /i/ dan /u/ sering kali tidak disuarakan apabila terdapat di antara konsonan tak berbunyi. Semua bunyi tersebut diucapkan sebagai satuan bunyi, vokal digunakan sendiri, atau didahului bunyi konsonan, atau konsonan dan semi vokal. Satuan bunyi dalam bahasa Jepang yang disebut mora, didasarkan pada lima buah vokal: /a/, /i/, /u/, /e/, dan /o/. Bunyi Pelafalan bunyi vokal panjang dalam bahasa Jepang panjangnya dua kali bunyi vokal pendek. Berdasarkan panjang pendeknya bunyi vokal ini, arti katanya akan berubah.

Unsur supra-segmental mengacu pada berbagai bentuk intonasi dan bagaimana kata dan kalimat diucapkan (Mirfatemi, Sadeghi \& Niyazi, 2020). Berdasarkan data penelitian, intonasi menjadi unsur yang menyebabkan terjadinya gegar bahasa. Dalam bahasa Jepang, intonasi terbagi menjadi tiga jenis, yaitu: (1) datar, (2) naik, dan (3) turun. Pertanyaan dilafalkan dengan intonasi yang menaik. Selain itu biasanya dilafalkan dengan intonasi datar, namun kadang-kadang dilafalkan dengan intonasi menurun untuk menunjukkan rasa persetujuan, kekecewaan, dan lain-lain. Bagi subjek penelitian, aspek segmental dan suprasegmental ini menimbulkan kesulitan tersendiri dalam memahami maksud lawan bicaranya. Hal ini terutama dirasakannya ketika lawan bicaranya berbicara sangat cepat.

\section{b. Tataran Morfologi}

Gegar bahasa pada tataran morfologi terjadi pada unsur kosakata dan aksara kanji. Dalam wawancara, subjek penelitian menyatakan sebagai berikut.

\author{
Kode \\ Morfologi (Morf)
}

Sumber
Wawancara melalui
video-call

Data

"Banyak sekali kosakata bahasa Jepang yang belum saya kuasai. Berkomunikasi dengan penutur asli adalah yang paling sulit; seringkali saya harus berusaha menjelaskan maksud saya dengan bahasa isyarat. Contohnya, ketika berusaha mencari electric fitting untuk laptop saja, saya harus membawa-bawa laptop kemana-mana, karena saya tidak tahu bagaimana mengatakan "colokan gepeng...."

Bahasa Jepang mempunyai jenis kosakata yang dibagi menjadi empat golongan yaitu Wago, Kango, Konshugo, dan Gairaigo. Wago adalah kata yang berasal dari bahasa Jepang, Kango dan Gairaigo adalah kata yang termasuk dari Cina dan negara asing lainnya atau dengan kata lain disebut juga sebagai kata pinjaman (Shayougo). Sedangkan yang dimaksud dengan Konshugo adalah kata yang merupakan gabungan lebih dari dua jenis bahasa dari tiga jenis bahasa yang disebut di atas.

Seiring perkembangan zaman, bahasa Jepang juga mengalami perkembangan dalam hal kosakata. Kosakata yang dilihat dan didengar tentunya banyak menggunakan istilah-istilah asing yang diserap dari berbagai negara dan dipakai di Jepang dan kosakata tersebut digunakan di berbagai bidang maupun dalam 
kehidupan sehari-hari. Perkembangan kosakata ini merupakan salah satu hal yang harus lebih dipelajari oleh subjek penelitian.

Dalam sebuah sesi wawancara, subjek penelitian menceritakan pengalamannya ketika diundang ke dalam kelas Bahasa Indonesia bagi mahasiswa Jepang. Di perguruan tinggi mitra tersebut, mahasiswa pertukaran yang berasal dari Universitas Indonesia dipandang sudah mahir berbahasa Jepang dan menguasai Kanji, sementara subjek penelitian merasa belum menguasai seluruh Kanji. Dalam status Facebook-nya, subjek penelitian menulis data berikut.

$\begin{array}{ccc}\text { Kode } & \text { Sumber } & \text { Data } \\ \text { Morfologi (Morf) } & \begin{array}{c}\text { Laman Facebook subjek } \\ \text { penelitian }\end{array} & \begin{array}{l}\text { "Ooh } \sim \text { So why Indonesia's Todai rep can't even } \\ \text { write kanji? } ~\end{array}\end{array}$

Ketika dikonfirmasi, subjek penelitian mengatakan bahwa ekspresi tersebut adalah perasaannya sendiri. Ia merasakan kurangnya kemampuan diri dalam menulis Kanji. Padahal selama ini mahasiswa pertukaran adalah mereka yang memiliki catatan prestasi akademik tinggi.

Dalam bahasa Jepang, ragam lisan disebut dengan hanashikotoba, sedangkan ragam tulisan disebut dengan kakikotoba. Berbeda dengan bahasa asing lainnya, huruf atau aksara yang dipergunakan untuk menulis kalimat dalam bahasa Jepang, mempunyai karakteristik tersendiri, yaitu huruf-huruf yang beraneka ragam, di antaranya Hiragana, Katakana, Romaji, dan Kanji. Aksara Hiragana dan Katakana menunjukkan bunyinya, dan pada umumnya satu Kana mewakili sebuah mora (satuan bunyi bahasa Jepang). Sedangkan Kanji menunjukkan artinya dan juga bunyinya.

Sekalipun ada aksara Hiragana dan Katakana, Kanji sebagai salah satu aksara yang digunakan dalam bahasa Jepang, memegang peranan yang sangat penting untuk dapat berkomunikasi dengan orang Jepang melalui tulisan. Kanji merupakan bagian yang tidak bisa dipisahkan dari bahasa Jepang. Aksara Kanji disamping memiliki arti, juga dibaca dalam dua cara yaitu cara baca Jepang (kun'yomi) dan cara baca Cina (on'yomi). Sejumlah 1945 Kanji ditentukan sebagai Kanji yang perlu dipergunakan sehari-hari.

Dibandingkan dengan bahasa Indonesia yang hanya menggunakan aksara latin, penggunaan aksara Kanji, Hiragana, dan Katakana menimbulkan tantangan tersendiri bagi subjek penelitian. Hal yang terberat dirasakan Subjek adalah ketika menempuh mata kuliah penulisan ilmiah, yang menuntut penguasaan aksara Kanji yang tinggi. Dari seluruh pengalaman subjek penelitian dalam hal gegar bahasa, aspek aksara Kanji merupakan hal yang paling berat bagi dirinya.

\section{c. Tataran Ragam Bahasa}

Dalam wawancara, Subjek menceritakan pengalamannya berkomunikasi dengan lawan bicara yang lebih senior dan beberapa kali salah menggunakan ragam hormat. Pengalaman ini disamakannya dengan tokoh dalam film animasi Jepang berjudul Lucky Star. Dalam film ini, karakter Patricia Martin digambarkan sebagai siswa transfer dari Amerika yang belajar bahasa Jepang dari komik dan anime (animasi Jepang) sehingga pilihan bahasanya sering kali dianggap tidak wajar/aneh. subjek penelitian merasakan hal yang serupa dengan karakter animasi tersebut karena mengalami kesulitan menentukan ragam bahasa yang sesuai bagi lawan 
bicaranya. Jika dalam bahasa Indonesia menggunakan pemarkah kesantunan untuk berbicara kepada orang yang lebih tua, misalnya, maka dalam bahasa Jepang kata kerja juga akan berubah sesuai dengan kedudukan atau posisi sosial lawan bicara. Ekspresi subjek penelitian dalam hal ini dituliskannya dalam status Facebook.

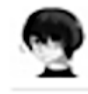

May 1 (2)

Here, I feel like Patricia Martin. Doesn't even bother to hide my power level and speaks BORKEN Japanese,

Like - Comment - Share

\title{
Gambar 1. Contoh Gegar Pada Tataran Ragam Bahasa (Sumber: Facebook)
}

\author{
Kode \\ Ragam Bahasa (RB) \\ Sumber \\ Laman Facebook \\ subjek penelitian
}

Data
"Here, I feel like Patricia Martin. Doesn't even bother to hide my power level and speak BORKEN Japanese."

Kata berbahasa Inggris BROKEN sengaja ditulis salah menjadi BORKEN, padahal subjek penelitian memiliki kemampuan berbahasa Inggris pada level lanjut. Kesalahan yang disengaja tersebut dilakukan subjek penelitian sebagai ekspresi dari ungkapan perasaannya yang merasa dirinya seperti Patricia Martin, jelasnya dalam wawancara.

\section{Pengaruh Gegar Bahasa terhadap Akulturasi Sosial Pemelajar}

Pada salah satu statusnya, subjek penelitian menuliskan: "I won't lie. Living alone for the first time in the Land of rising Sun is far from easy. But to be able to take afternoon walk under the cherry blossoms...It's more than "worth it."

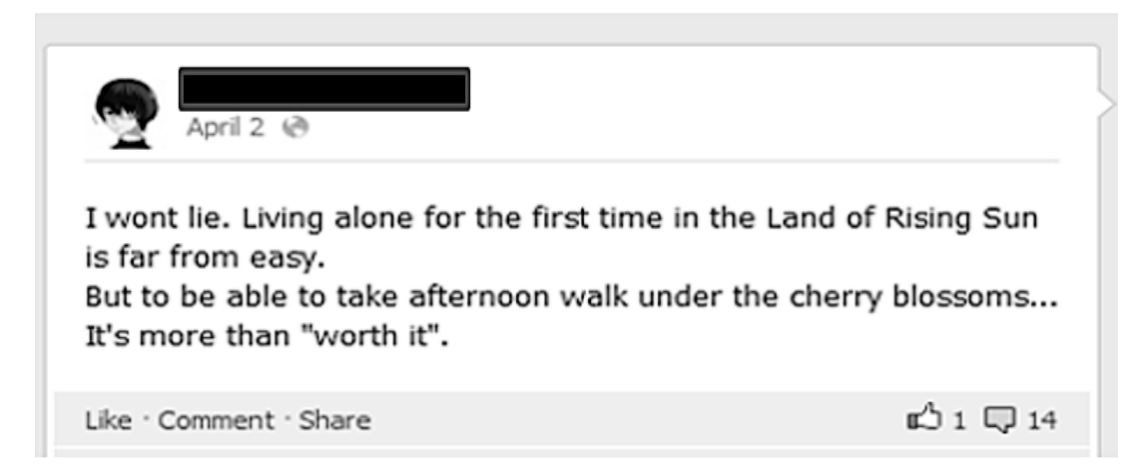

\section{Gambar 2. Ekspresi di Tahapan Initial Adjustment (Sumber: Facebook)}


Ekspresi tersebut menggambarkan tahapan proses penyesuaian subjek penelitian kepada lingkungannya. Proses penyesuaian singkat bagi lama tinggal 1 tahun dalam sebuah negara terdiri dari tahap-tahap: (1) honeymoon period, (2) culture shock, 3) initial adjustment, (4) depression/mental isolation, dan (5) acceptance and integration.

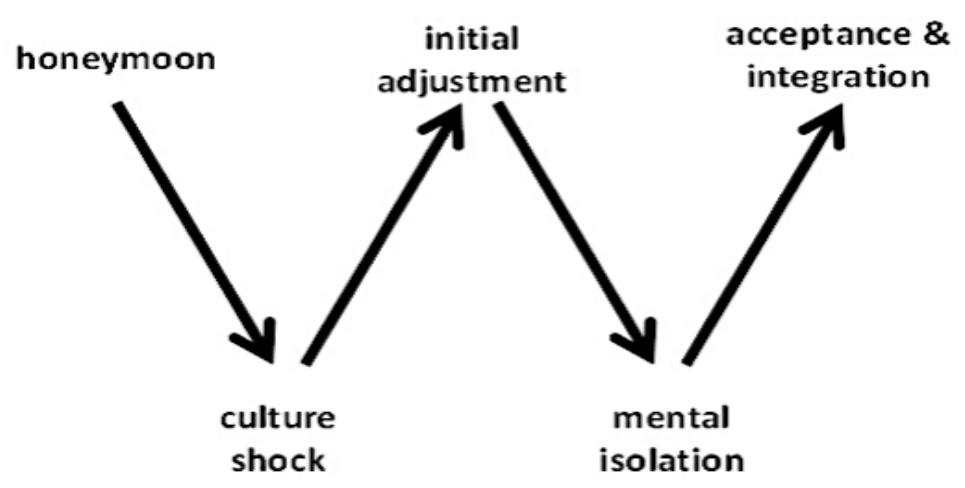

Gambar 3: Tahapan Proses Penyesuaian Budaya (Sumber: Levine)

Penelitian menunjukkan bahwa setelah seseorang masuk ke dalam sebuah lingkungan budaya baru, dan bereaksi secara berbeda-beda pula terhadap lingkungan barunya, biasanya kemudian terjadi proses penyesuaian. Terdapat tahapan-tahapan yang jelas dalam proses penyesuaian diri ini (Levine, 1993). Walaupun kelak tahaptahap tersebut tidak dilalui secara lengkap, penyesuaian seperti inilah akan memungkinkan pendatang baru untuk berfungsi dan kadang kala berhasil di dalam negara baru tersebut. Berdasarkan data yang bersumber pada Gambar 3, subjek penelitian telah berada pada tahap ketiga, yaitu Initial Adjustment. Gegar budaya masih dirasa berat olehnya, tetapi sudah diimbangi dengan perasaan puas karena dapat merasakan indahnya berjalan-jalan di antara bunga-bunga Cherry yang bermekaran.

Namun pada bulan selanjutnya subjek penelitian memasuki tahap keempat yaitu Depression, akibat hilangnya semua tanda dan simbol hubungan sosial yang biasa dikenalnya. Hal ini dapat dipahami karena terdapat perbedaan besar antara budaya Indonesia dengan budaya Jepang. Mahasiswa pertukaran ini mengalami kesulitan dalam menyesuaikan diri dan merasakan kurangnya keterampilan yang diungkapkannya dalam status berikut:

\footnotetext{
Kode

Data

Gegar Bahasa:

depression/mental isolation

"Oh...shut up! What needed is the ability to READ, not WRITE, you bloody dimwit."
}

Hal yang terjadi pada subjek penelitian tersebut telah disinggung oleh Oberg (1954) sebagai salah satu bentuk kecemasan akibat hilangnya semua tanda dan simbol hubungan sosial yang biasa dikenal oleh seseorang yang berada pada terjadinya proses pemahaman lintas budaya. Proses ini juga menjadi salah satu alasan munculnya gegar budaya dan bahasa. Cupsa (2018) menegaskan bahwa gegar 
budaya dan bahasa dialami secara sadar dan tidak sadar. Mahasiswa ataupun orang yang mengalaminya hanya bisa merasakan bahwa mereka tidak dapat memfungsikan keterampilan bahasa dan komunikasi mereka dengan optimal. Dari sisi positif, orang yang mengalami gegar budaya dan bahasa dipandang sebagai peserta aktif dalam bernegosiasi dengan realitas baru melalui penyelesaian masalah. Namun sayangnya, dalam studi kontak antar budaya, kata gegar digunakan untuk menunjukkan terdapatnya defisit keterampilan (Ward, Bochner, \& Furnham, 2001)

Kembali kepada model akulturasi sosial Schumann, maka subjek penelitian telah dipengaruhi oleh sikap negatif yang bisa menjadi penghalang suksesnya kontak antar budaya. Sikap tersebut berasal dari (1) pengalaman kesulitan berbicara menggunakan bahasa target sehingga membuat pemelajar merasa bodoh atau memalukan; dan (2) merasa disorientasi dan tidak nyaman dalam sebuah budaya baru sehingga lebih memilih mengidentifikasi dirinya dengan tokoh yang dianggap aneh dan tidak wajar. Namun, di sisi lain, dengan subjek penelitian telah berada pada tahap isolasi mental maka telah terjadi proses penyesuaian pemelajar dengan sebuah identitas baru yang diasosiasikan dengan segala yang terkait dengan komunitas tutur. Kelak, saat akan kembali ke tanah air, proses penyesuaian dan akulturasi sosial akan sempurna dan pemelajar diharapkan akan berhasil menguasai bahasa target. Hal ini sesuai dengan pendapat Nida (2003) yang menyatakan bahwa faktor-faktor seperti entitas, peristiwa, keadaan, proses, dan karakteristik sebuah budaya memiliki pengaruh yang kuat pada konten bahasa yang digunakan dalam budaya tersebut. Akan tetapi bahasa juga secara relatif memberikan dampak pada budaya yang melekat.

\section{PENUTUP}

Penelitian ini bertujuan menggambarkan proses gegar bahasa yang dialami oleh mahasiswa pertukaran Indonesia di Jepang. Program pertukaran dengan perguruan tinggi mitra di luar negeri diharapkan dapat memfasilitasi belajar bahasa dan budaya langsung dari sumbernya bagi peserta. Namun demikian, mempelajari bahasa secara alamiah pada lingkungan bahasa target bukannya tanpa hambatan. Perpindahan dari satu lingkungan bahasa dan budaya ke lingkungan yang berbeda pada umumnya diawali dengan terjadinya gegar budaya (culture shock) dan gegar bahasa (language shock). Karena bahasa dan budaya merupakan dua hal yang sangat berkaitan, perbedaan bahasa dapat mengarah pada gegar budaya, atau dengan kata lain, gegar budaya dapat terjadi karena perbedaan-perbedaan linguistik antar bahasa asal pemelajar dengan bahasa target.

Berdasarkan uraian pada pembahasan di atas, maka dapat disimpulkan bahwa: (1) gegar bahasa yang dialami subjek penelitian dalam lingkungan bahasa target meliputi aspek linguistik dan sosiolinguistik; (2) gegar bahasa berdasarkan aspek linguistik meliputi: tataran fonologi yaitu pada fonem segmental dan suprasegmental, dan tataran morfologi yaitu pada kosakata dan aksara Kanji; dan (3) gegar bahasa berdasarkan aspek sosiolinguistik meliputi penggunaan ragam bahasa, yaitu ragam hormat.

Oleh karena itu, penelitian ini merekomendasikan untuk mengeksplorasi lebih jauh pengaruh gegar budaya dan bahasa terhadap pembelajaran bahasa pada saat pertukaran mahasiswa. Dengan demikian diharapkan dapat memberikan peluang intervensi yang bisa dilakukan oleh perguruan tinggi untuk lebih mempersiapkan mahasiswa sebelum keberangkatannya guna kesuksesan belajar bahasa. 


\section{DAFTAR PUSTAKA}

Agar, M. (2002). Language Shock: Understanding the Culture of Conversation. New York: Perennial.

Bogdan, R. C., \& Biklen, S. K. (2007). Qualitative Research for Education: An Introduction to Theory and Methods. $5^{\text {th }}$ Edition. Boston: Pearson Education.

Chaer, A., \& Agustine, L. (1995). Sosiolinguistik: Perkenalan Awal. Jakarta: Rinneka Cipta.

Cupsa, I. (2018). Culture Shock and Identity. Transactional Analysis Journal, 48(2), 181-191. https://doi.org/10.1080/03621537.2018.1431467

Daytner, K. M. (2006). Validity in Qualitative Research: Application of Safeguards. Proceeding Annual Meeting of the Ethnographic and Qualitative Research in Education Conference. https://files.eric.ed.gov/fulltext/ED516416.pdf

Engle, L., \& Engle, J. (2003). Study Abroad Levels: Toward a Classification of Program Types. Frontiers: The Interdisciplinary Journal of Study Abroad, 9(1), 1-20. https://doi.org/10.36366/frontiers.v9i1.113

Fan, S. (2010). Language Shock: A Challenge to Language Learning. The International Journal of Language Society and Culture, 31(2), 42-51. https://aaref.com.au/wp-content/uploads/2018/05/31-6.pdf

Graham, C. R., \& Brown, C. (1996). The Effects of Acculturation on Second Language Proficiency in a Community with a Two-Way Bilingual Program. Bilingual Research Journal, 20(2), 235-260. https://doi.org/10.1080/15235882.1996.10668629

Harris, N., Miles, D., Howard, E., Zuchowski, I., King, J., Dhephasadin Na Ayudhaya, P., ... Puthantharayil, G. (2017). International Student Exchange in Australian Social Work Education. Australian Social Work, 70(4), 429-440. https://doi.org/10.1080/0312407X.2017.1309671

Khan, R. M., \& Khan, M. A. (2007). Academic Sojourners, Culture Shock and Intercultural Adaption: A Trend Analysis. Kalbu Studijos, 10, 38-46. https: / / www.ceeol.com/search/article-detail?id $=55005$

Levine, D. R., \& Adelxman, M. R. (1993). Beyond Language: Cross-Cultural Communication. New Jersey: Prentice Hall.

McKay, S., Lannegrand, L., Skues, J., \& Wise, L. (2020). Identity Development During Student Exchange: A Qualitative Study of Students' Perspectives on the Processes of Change. Emerging Adulthood. https://doi.org/10.1177/2167696820969464

Mills, A. J., Durepos, G., \& Wiebe, E. (2010). Encyclopedia of Case Study Research. Los Angele: Sage Publications.

Mirfatemi, F., Sadeghi, A., \& Niyazi, M. P. (2020). Impact of Supra-Segmental Features on Reading Comprehension in First and Second Language: A Comparative Study of Iranian EFL Learners. Language Teaching Research Quarterly, 20, 19-42. https://doi.org/10.32038/ltrq.2020.20.02

Oberg, K. (1954). Culture Shock. Presentation to the Women's Club, Rio de Janeiro, Brazil. Diperoleh dari https://citeseerx.ist.psu.edu/viewdoc/download?doi=10.1.1.461.5459\&rep=r ep1\&type $=$ pdf

Redden, E. (2010). Academic Outcomes of Study Abroad. Diperoleh dari http://www.insidehighered.com/news/2010/07/13/abroad\#ixzz20JI6Az9A 
Schumann, J. H. (1986). Research on the Acculturation Model for Second Language Acquisition. Journal of Multilingual and Multicultural Development, 7(5), 379-392. http://dx.doi.org/10.1080/01434632.1986.9994254

Ward, C., Bochner, S., \& Furnham, A. (2001). The Psychology of Culture Shock. $2^{\text {nd }}$ Edition. Hove: Routledge.

Wardhaugh, R. (2002). An Introduction to Sociolinguistics. Fourth Ed. Malden: Blackwell Publishing.

Wray, A., Trout, K., \& Bloomer, A. (1998). Project in Linguistics. UK: Hodder Arnold Publication.

Yin, R. K. (2003). Case Study Research, Design and Methods. $3^{\text {rd }}$ Edition. Thousand Oaks: Sage Publications. 
